\title{
Short-Stay Surgery: Impact of Opening a New Unit in a Tertiary Urban Hospital
}

\author{
Albert Salazar*, Carme Bello, Rosa Muñoz, Ferran Caballero, Carme Rullo, Carme Zaldivar, \\ Xavier Martin, Margarita Esteve, Gemma Craywinckel
}

Hospital de la Santa Creu i Sant Pau, Universitat Autònoma Barcelona, Barcelona, Spain

Email: *ASalazar@santpau.cat

How to cite this paper: Salazar, A., Bello, C., Muñoz, R., Caballero, F., Rullo, C., Zaldivar, C., Martin, X., Esteve, M. and Craywinckel, G. (2016) Short-Stay Surgery: Impact of Opening a New Unit in a Tertiary Urban Hospital. International Journal of Clinical Medicine, 7, 723-725.

http://dx.doi.org/10.4236/ijcm.2016.711078

Received: May 25, 2016

Accepted: October 29, 2016

Published: November 1, 2016

Copyright @ 2016 by authors and Scientific Research Publishing Inc. This work is licensed under the Creative Commons Attribution International License (CC BY 4.0).

http://creativecommons.org/licenses/by/4.0/

\begin{abstract}
Objective: The number of procedures considered suitable for short-stay surgery has experienced a remarkable increase. The objective of the study was to determine whether a new short-stay surgical unit (SSSU) was an effective alternative to conventional Hospital Units (HU) for selected elective and urgent surgical conditions. Methods: A comparative analysis (Mann-Whitney test) was used to identify differences between patients admitted to HU $(n=2873)$ and those admitted to the SSSU $(n=$ 544) during the following months (January 1, 2014 to August 31, 2014, and January 1, 2015 to August 31, 2015, respectively). Results: Statistically significant differences were found in terms of mean length of stay (HU: 4.8 days versus SSSU: 2.2 days; $P<$ 0.0001 ), and a number of associated conditions (HU: 1.37 versus SSSU: $1.09 ; P=$ 0.02). There were no statistically significant differences regarding age and sex. Conclusions: We conclude that selected surgical patients with elective or acute conditions can be effectively treated in the SSSU.
\end{abstract}

\section{Keywords}

Surgery, Short-Stay, Hospital, Management

\section{Introduction}

In recent years, the number of procedures considered suitable for short-stay surgery has experienced a remarkable increase. Pre-operative preparation and protocol discharge have contributed to a safe and effective short-stay surgery for patients presenting elective conditions and some acute conditions requiring urgent surgery [1]. However, there are few data to establish the duration of hospitalization in individual patients to achieve maximal benefit and to identify those patients suitable for early discharge from the hospital. 
The objective of the study was to determine whether a new short-stay surgical unit (SSSU) was an effective alternative to conventional Hospital Units (HU) for selected elective and urgent surgical conditions.

\section{Methods}

A comparative analysis (Mann-Whitney test) was used to identify differences between patients admitted to HU $(\mathrm{n}=2873)$ and those admitted to the SSSU $(\mathrm{n}=544)$ during the following months (January 1, 2014, to August 31, 2014, and January 1, 2015, to August 31, 2015, respectively). The study was performed at Sant Pau Hospital, a 500bed teaching tertiary care referral centre in Barcelona, Spain. The emergency department attends about 130,000 emergency visits per year, including pediatrics and obstetrics. We retrospectively studied the characteristics of patients hospitalized during both periods of the study with the same diagnoses $(n=3417)$. We chose charts of patients from the hospital discharge database and selected according to the Ninth Revision of the International Classification of Diseases codes. We used the computerized database to obtain outcome data on all patients. Clinical and demographic factors were available through chart review. Patients were excluded from the study if they were intubated and ventilated on the day of admission.

\section{Results}

Statistically significant differences were found in terms of mean length of stay (HU: 4.8 days versus SSSU: 2.2 days; $P<0.0001$ ), and number of associated conditions (HU: 1.37 versus SSSU: $1.09 ; P=0.02$ ). There were no statistically significant differences regarding age and sex.

\section{Discussion}

The strength of our study includes a large sample size. We demonstrated that the introduction of an SSSU at a tertiary university hospital was associated with a decrease in the patients' length of stay. It is likely that part of the increased length of stay for the HU group is a feature of the nature and function of inpatient services. It is important to note that the comorbidity, measured as a number of associated conditions, in HU was significantly higher, which cannot rule out a possible bias effect of less seriously ill patients admitted to the new SSSU.

The definition of short-stay surgery includes those patients admitted and discharged between 24 hours and 72 hours. The complexity of procedures performed with minimally invasive surgery leads to a wide range of patients to be implemented as shortterm surgery [2] [3]. This management can improve the quality of patient care, particularly postoperative recovery, while reducing length of stay [4]. Shortened hospital stay is basic to modern patient care and also reduces hospital-acquired infections and venous thromboembolism [5].

A multidisciplinary approach is recommended for patient assessment including inclusion and exclusion criteria for short-stay surgery. Social, medical and surgical factors 
should be appropriate for postoperative care. Documentation is important from preoperative preparation to discharge and follow-up. Patients should be provided with general as well as procedure-specific information. Integrated care pathways are useful for evaluation of outcomes [6].

Staff working in these units should be specifically trained in surgery care and must have a clinical lead with interest in the development of local guidelines and clinical governance.

However, several important limitations must be addressed. First, readmission rate was not recorded to compare the occurrence of relapse after discharge that could have suggested the need for intensified ambulatory care or home care in the weeks after a short admission in an SSSU. And, as we did not conduct a formal economic analysis, further work is needed to quantify the economic impact of the introduction of an SSSU in the management of surgical conditions.

We conclude that selected surgical patients with elective or acute conditions can be effectively treated in the SSSU. The identification of these patients proved to be an effective measure in hospital management and a helpful intervention that alleviated in-hospital bed crises.

\section{References}

[1] Verma, R., Alladi, R., Jackson, I., Johnston, I., Kumar, C., Page, R., Smith, I., Stocker, M., Tickner, C., Williams, S. and Young, R. (2011) Guidelines: Day Case and Short Stay Surgery: 2. Anaesthesia, 66, 417-434. http://dx.doi.org/10.1111/j.1365-2044.2011.06651.x

[2] Smith, I. (2009) Emergency Day Surgery. Journal of One-Day Surgery, 19, 2-3.

[3] Miyagy, K., Yao, C., Lazenby, K., Himpson, R. and Ingham Clark, C.L. (2009) Use of the Day Surgery Unit for Emergency Surgical Cases. Journal of One-Day Surgery, 19, 5-8.

[4] Chung, F., Kayumov, L., Sinclair, D.R., Edward, R., Moller, H.J. and Shapiro, C.M. (2005) What Is the Driving Performance of Ambulatory Surgical Patients after General Anesthesia? Anesthesiology, 103, 951-956. http://dx.doi.org/10.1097/00000542-200511000-00008

[5] Corbella, X., Ortiga, B., Juan, A., Ortega, N., Gomez, C., Capdevila, C., Bardes, I., Alonso, G., Ferre, C., Soler, M., Mañez, R., Jaurrieta, E., Pujol, R. and Salazar, A. (2013) Alternatives to Conventional Hospitalization for Improving Lack of Access to Inpatient Beds: A 12-Year Cross-Sectional Analysis. Journal of Hospital Administration, 2, 9-21.

[6] Tickner, C. (2009) Health Care Assistant Enabled Discharge. Journal of One-Day Surgery, 17, 106-109. 
Submit or recommend next manuscript to SCIRP and we will provide best service for you:

Accepting pre-submission inquiries through Email, Facebook, LinkedIn, Twitter, etc. A wide selection of journals (inclusive of 9 subjects, more than 200 journals)

Providing 24-hour high-quality service

User-friendly online submission system

Fair and swift peer-review system

Efficient typesetting and proofreading procedure

Display of the result of downloads and visits, as well as the number of cited articles

Maximum dissemination of your research work

Submit your manuscript at: http://papersubmission.scirp.org/

Or contactijcm@scirp.org 